\title{
Failure of Premature Rabbits to Increase Lung Antioxidant Enzyme Activities after Hyperoxic Exposure: Antioxidant Enzyme Gene Expression and Pharmacologic Intervention with Endotoxin and Dexamethasone
}

\author{
ILENE R. S. SOSENKO, YOUWEI CHEN, LALITHA T. PRICE, AND LEE FRANK \\ Divisions of Neonatology and Pulmonary Research, Departments of Pediatrics and Internal Medicine, \\ University of Miami School of Medicine, Miami, Florida 33101
}

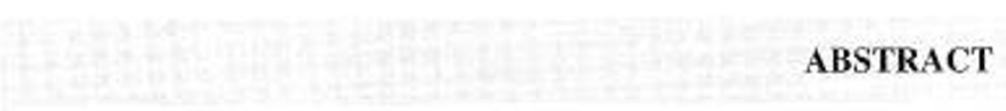

\begin{abstract}
Premature rabbits, unlike full-term rabbits, are unable to mount a protective increase in pulmonary antioxidant enzyme (AOE) activities in response to $48 \mathrm{~h}$ of hyperoxic exposure and demonstrate increased pulmonary $\mathrm{O}_{2}$ toxicity compared with full-term rabbits. To examine $\mathrm{AOE}$ gene expression of $\mathrm{CuZn}$ superoxide dismutase (SOD), Mn SOD, catalase, and glutathione peroxidase in preterm versus term rabbits in response to hyperoxia, $29.5 \mathrm{~d}$ preterm rabbits (delivered by hysterotomy) and term rabbits (spontaneously vaginally delivered) were exposed to $48 \mathrm{~h}$ of $>90 \% \mathrm{O}_{2}$ or room air. Preterm rabbits had a significant increase in CuZn SOD mRNA without corresponding $\mathrm{AOE}$ activity increases, suggesting translational/posttranslational inhibition. In full-term rabbits, the magnitude of lung AOE mRNA changes was associated with concordant magnitude changes in activities of $\mathrm{CuZn}$ SOD, Mn SOD, and catalase, suggesting pretranslational regulation of AOE gene expression; glutathione peroxidase, however, appears to be regulated translationally/ posttranslationally. To investigate potential pharmacologic means of overcoming the susceptibility of the preterm rabbit to $\mathrm{O}_{2}$ toxicity, $29.5 \mathrm{~d}$ preterm rabbits received $20-40 \mu \mathrm{g} / \mathrm{kg}$ of Salmonella typhimurium endotoxin or diluent S.C. (after birth and at $24 \mathrm{~h}$ ); in separate experiments, pregnant rabbits received intramuscular injections of dexamethasone $(0.01-0.05 \mathrm{mg} / \mathrm{kg}$ ) or
\end{abstract}

The incidence of chronic lung disease in human premature infants increases with decreasing gestational age (1) and is thought to be related in part to oxygen free radical-induced lung injury. In an attempt to explain the mechanisms involved with this chronic lung process and these epidemiologic observations, we have previously demonstrated that premature rabbits have decreased baseline activity levels of pulmonary AOE (2) and are also unable to mount a protective increase in $\mathrm{AOE}$

Received August 19, 1994; accepted December 1, 1994.

Correspondence and reprint requests: Ilene R.S. Sosenko, M.D., Department of Pediatrics (R-131), University of Miami School of Medicine, PO Box 016960, Miami, FL 33101 . saline on gestational d 27.5 and 28.5 and underwent hysterotomy at 29.5 d. After hyperoxic exposure, postnatal endotoxin treatment of preterm rabbits resulted in significant increases in $\mathrm{CuZn}$ SOD activity and CuZn SOD mRNA, suggesting a reversal of the translational/posttranslational inhibition characteristic of the preterm rabbit, improved hyperoxic survival $(74 / 81=91 \%$ versus $70 / 92=76 \%, p<0.05$; endotoxin versus controls), and protection against hyperoxia-induced increases in lung lavage protein $(+4 \%$ endotoxin versus $+28 \%$ controls, $p<0.05)$. Prenatal dexamethasone neither improved hyperoxic survival, protected against $\mathrm{O}_{2}$ toxicity, nor produced increases in any of the AOE after $48 \mathrm{~h}$ of hyperoxia relative to air-breathing preterm rabbits. (Pediatr Res 37: 469-475, 1995)
AOE, antioxidant enzymes
SOD, superoxide dismutase
CuZn SOD, copper,zinc superoxide dismutase
Mn SOD, manganese superoxide dismutase
CAT, catalase
GP, glutathione peroxidase
DSPC, disaturated phosphatidylcholine
cRNA, complementary RNA

Abbreviations

activities in response to $48-72$ h of hyperoxic exposure (3). Conversely, full-term newborn rabbits are able to significantly increase AOE activities with hyperoxia (3). Compared with term rabbits, which demonstrate minimal evidence of hyperoxic lung damage, preterm rabbits manifest increases in several indices of pulmonary $\mathrm{O}_{2}$ toxicity, including lung lavage fluid protein content, lung conjugated diene levels, and light microscopic lung pathology (3).

We undertook the present study to investigate the molecular basis for the lack of hyperoxic AOE induction in preterm rabbits and its presence in term rabbits, and examined $\mathrm{AOE}$ gene expression after hyperoxic exposure at these two different 
gestational ages. In addition, to explore potential pharmacologic means of overcoming the susceptibility of the preterm rabbit to $\mathrm{O}_{2}$ toxicity, we investigated whether, in the preterm rabbit, postnatal treatment with Salmonella typhimurium endotoxin or antenatal trcatment with dexamethasone could reverse the early $\mathrm{O}_{2}$ toxicity changes previously observed and/or reverse the inability of the preterm rabbit to induce a protective hyperoxic increase in pulmonary AOE activities. We also cxamined hyperoxic AOE gene expression after postnatal endotoxin or prenatal dexamethasone treatment.

\section{METHODS}

\section{Animals}

Timed-pregnant New Zealand albino rabbits were obtained from a local supplier (K-W Farms, Ft. Myers, FL), transported at least 1 week before term, and housed at the University of Miami Animal Care Facility. All animal care and experimental procedures were preapproved by the University of Miami Committee on Research Animal Welfare. To obtain preterm rabbits, pregnant rabbits were subjected to premature delivery at gestational $\mathrm{d} 29.5$ by hysterotomy under ketamine/xylazine anesthesia (ketamine, $90 \mathrm{mg} / \mathrm{kg}$; xylazine, $10 \mathrm{mg} / \mathrm{kg}$ i.v.), after which the abdominal vessels were cut to kill the animal. Twenty-nine and one half days of gestation was selected because at this gestational age, the animals still satisfy the definition of prematurity and demonstrate an inability to induce a protective hypcroxic AOE activity response, yet most are capable of surviving without vigorous supportive care including $\mathrm{O}_{2}$ and mechanical ventilation (3). To obtain full-term newborn rabbits, pregnant rabbits were allowed to deliver spontaneously into breeder boxes at term (31-32 d).

The newly delivered $29.5 \mathrm{~d}$ rabbits were immediately resuscitated by drying, stimulation, 5-15 min of low flow $\mathrm{O}_{2}$, and warming in $30-32^{\circ} \mathrm{C}$ isolettes. This process yielded initial survival of $>90 \%$ of the preterm rabbits. Term rabbits were removed from their mothers within $18 \mathrm{~h}$ of delivery and placed into $30-32^{\circ} \mathrm{C}$ isolettes. Both the preterm and term rabbits were gavage fed via a 5 French feeding tube within $2 \mathrm{~h}$ of delivery for preterm rabbits and upon retrieval from their does for full-term rabbits and then at 24-h intervals with a simulated rabbit milk formula [consisting of casein hydrolysate (3\%), whey protein $(4.5 \%)$, corn oil $(3 \%)$, coconut oil $(3 \%)$, lactose $(1 \%)$, complete vitamin and mineral mix $(1 \%)$, and water to $100 \mathrm{~mL}$, providing approximately $100 \mathrm{kcal} / 100 \mathrm{~mL}$ (US Biochemicals, Cleveland, $\mathrm{OH}$, and ICN, Costa Mesa, CA) plus Mazola corn oil]. The volume administered was $6 \mathrm{~mL} / 100 \mathrm{~g}$ body weight for the first feeding and $8 \mathrm{~mL} / 100 \mathrm{~g}$ after $24 \mathrm{~h}$. The diet enabled the preterm and newborn rabbits to maintain weight within $5-10 \%$ of birth weight but did not produce weight gain. However, newborn rabbits normally nurse once daily and do not gain body weight until after the third postnatal day (4).

For studies of $\mathrm{AOE}$ gene expression in preterm versus term newborn rabbits after hyperoxic exposure, 29.5-d pretcrm rabbits and spontaneously delivered term rabbits (who were removed from their mothers within $18 \mathrm{~h}$ of delivery) received no pharmacologic intervention, were weighed and numbered, re- ceived their first artificial feeding, and were then randomized to either hyperoxia or room air exposure.

\section{Pharmacologic Interventions}

For the postnatal endotoxin studies, 29.5-d preterm rabbits were delivered by hysterotomy, resuscitated as described above, weighed and numbered, fed, and then randomly assigned to receive either postnatal endotoxin treatment or to serve as controls. Endotoxin was administered s.c. within 2-3 $\mathrm{h}$ of delivery and then at $24 \mathrm{~h}$ in the form of lipopolysaccharide (Westphal extracted) S. typhimurium (Difco Labs, Detroit, MI) at doses ranging from 20 to $40 \mu \mathrm{g} / \mathrm{kg}$. Control preterm rabbits received equivolume s.c. injections of saline. The endotoxintreated and control preterm rabbits were again randomly divided for subsequent exposure to either hyperoxia $\left(>90 \% \mathrm{O}_{2}\right)$ or room air for $48 \mathrm{~h}$.

For the antenatal dexamethasone experiments, pregnant rabbits at 27.5 and $28.5 \mathrm{~d}$ of gestation received a once daily intramuscular injection of dexamethasone sodium phosphate (Steris Laboratories, Inc., Phoenix, AZ) at doses ranging from 0.01 to $0.05 \mathrm{mg} / \mathrm{kg}$ maternal body weight. Control pregnant rabbits received equivolume saline injections. After delivery and initial resuscitation, the 29.5 -d preterm rabbits from mothers receiving either dexamethasone or saline were weighed and numbered, fed, and then randomly divided for exposure to either hyperoxia $\left(>90 \% \mathrm{O}_{2}\right)$ or room air for $48 \mathrm{~h}$. In addition, a small number of randomly selected dexamethasone and control preterm rabbits were killed immediately after birth before air breathing to ascertain baseline AOE activities and lung DSPC content. In a separate experimental group of rabbits, rather than administering dexamethasone to the pregnant doe, we obtained preterm rabbits after hysterotomy delivery as described above, resuscitated them, and administered dexamethasone treatment postnatally within 1-2 h of delivery (and then $24 \mathrm{~h}$ later) at a dose of $5 \mu \mathrm{g} / \mathrm{kg}$, and randomly assigned them to either $>90 \% \mathrm{O}_{2}$ or room air exposure for $48 \mathrm{~h}$.

\section{Hyperoxia and Air Exposures}

The $29.5-\mathrm{d}$ preterm or term rabbits randomly assigned to hyperoxia were placed into $3.5-\mathrm{ft}^{3}$ exposure chambers (adapted from infant isolettes; Air Shields, Hatboro, PA) and received $>90 \% \mathrm{O}_{2}$ for $48 \mathrm{~h}$; the chambers were monitored several times daily for gas concentration with SensorMedics (Dayton, $\mathrm{OH}$ ) $\mathrm{O}_{2}$ and $\mathrm{CO}_{2}$ monitors. $\mathrm{CO}_{2}$ was maintained at $<0.4 \%$. Those assigned to room air exposure were placed in similar chambers and received room air flow $\left(21 \% \mathrm{O}_{2}\right)$ for a 48 -h period. Both groups received constant temperature $\left(32^{\circ} \mathrm{C}\right)$, humidity $(50-$ $70 \%$ ), and feeding conditions. Exposure to $>90 \% \mathrm{O}_{2}$ or room air was continuous for $48 \mathrm{~h}$, except for a daily 15 - to 20 -min period required for weighing, feeding, and cage cleaning (and for endotoxin experiments: endotoxin or saline injections).

\section{Biochemical Analyses}

After the 48-h hyperoxia or room air exposure period, the preterm or term rabbits were killed with an intraperitoneal ovcrdose of pentobarbital. The abdominal vessels were cut to 
exsanguinate the animals, the left atrial appendage was cut to facilitate drainage, and the lungs were perfused to whiteness via the pulmonary artery with cold saline. The lungs were then immediately frozen in liquid nitrogen and maintained at $-70^{\circ} \mathrm{C}$ before biochemical analyses. Some preterm rabbits in the prenatal dexamethasone treatment group were killed (with an intraperitoneal overdose of pentobarbital administered through the unopened amniotic sac) before air breathing, and their lungs were perfused and then frozen as above for subsequent analysis of baseline AOE activities and lung DSPC.

AOE activity determination. For AOE activity analyses, thawed lungs were subsequently weighed, homogenized in cold saline (1:15 wt/vol) (Brinkmann Polytron, Westbury, $\mathrm{NY}$ ), centrifuged for $45 \mathrm{~min}$ at $15000 \mathrm{rpm}$, and then assayed by standard spectrophotometric techniques for activities of total SOD (xanthine/xanthine oxidase method) (5), CAT (rate of reduction of $\mathrm{H}_{2} \mathrm{O}_{2}$ at $240 \mathrm{~nm}$ ) (6), and GP (rate of oxidation of NADPH at $340 \mathrm{~nm}$ using cumene hydroperoxide as substrate) (7). For the dexamethasone studies, only total SOD activity (in addition to CAT and GP) was measured. For determining CuZn SOD and Mn SOD activities, samples were desalted using a Bio Rad (Richmond, CA) Econo-Pac 10DG column and eluted in buffer containing $50 \mathrm{mM}$ potassium phosphate plus $0.1 \mathrm{mM}$ EDTA. Sample recovery was determined by comparing protein content (Coomassie Plus Protein assay, Pierce Co., Rockford, IL) in aliquots of samples before and after passage through the columns. After performing the xanthine/xanthine oxidase assay using both low concentrations $(0.015 \mathrm{mM})$ and high concentrations $(1.5 \mathrm{mM})$ of cyanide, CuZn SOD and Mn SOD activities were calculated as described by Iqbal and Whitney (8). Lung homogenates were also assayed for total DNA (9) and protein (10) content. Purified standards for SOD, CAT, DNA, and protein assays were obtained from Sigma Chemical Co. (St. Louis, MO); GP standard was obtained from Boehringer-Mannheim (Indianapolis, IN). AOE activity was expressed per mg of DNA.

AOE mRNA quantitation. Preparation of cRNA was performed as described previously $(11,12)$. Total nucleic acids were isolated from lung tissue according to published methodology (13). Samples of total nucleic acid solutions were then exposed to the ${ }^{35} \mathrm{~S}$-radiolabeled antisense cRNA probes for CuZn SOD mRNA, Mn SOD mRNA, CAT mRNA, and GP mRNA to quantitate these mRNA using solution hybridization (14). The unlabeled sense cRNA (of CuZn SOD, Mn SOD, CAT, and GP) were used as a standard to define the range in which hybridization of each radiolabeled probe increased pro- portionately with added mRNA. Results of mRNA concentrations were expressed as specific mRNA molecules per mg of DNA.

DSPC analysis. Aliquots of lung homogenate were subjected to lipid extraction according to the method of Bligh and Dyer (15), reacted with osmium tetroxide as described by Mason et al. (16) to isolate the DSPC, and then assayed for inorganic phosphorus using the method of Morrison (17). A known quantity of ${ }^{14} \mathrm{C}$-dipalmitoylphosphatidylcholine (New England Nuclear, Boston, MA) was added before lipid extraction to estimate and correct for sequential losses. DSPC was expressed as $\mathrm{mg} / \mathrm{g}$ wet lung weight.

\section{Indices of $\mathrm{O}_{2}$ Toxicity}

Daily survival was determined in both hyperoxia and room air exposure groups. In addition, randomly selected, unperfused right upper lobes of lungs from $\mathrm{O}_{2}$-exposed and room air-exposed preterm rabbits from the endotoxin and dexamethasone studies were subjected to wet lung weight/dry lung weight ratio measurements to roughly assess the effect of hyperoxia and specific pharmacologic interventions on lung water content. After the 48-h hyperoxia and room air exposure periods, as part of the endotoxin and dexamethasone experiments, randomly selected lungs were lavaged via a trachcal cannula with cold saline immediately after the rabbits were killed. Three lavages were performed using the volume necessary to fully inflate the right lung (the left lung had been clamped); the fluid was pooled and then measured for lavage protein content (10).

\section{Statistical Analysis}

Analysis of variance was used for comparing the four animal groups in each study. This was followed by Duncan's multiple range test with a $p$ value $<0.05$ used to indicate significant differences between the groups. Survival between groups was compared using $\chi^{2}$ analysis (18).

\section{RESULTS}

$A O E$ gene expression in preterm versus term rabbits. In association with the inability to increase lung AOE activities after $48 \mathrm{~h}$ of hyperoxic exposure (saline-control values, Tables 1 and 2), 29.5-d preterm rabbits demonstrated significant increases in CuZn SOD mRNA $(+30 \%, p<0.05)$ as wcll as elevations (which were not statistically significant) in Mn SOD

Table 1. AOE activities and lung DSPC after 48-h air or $>90 \% \mathrm{O}_{2}$ exposure in endotoxin-treated and control 29.5-d preterm rabbits

\begin{tabular}{|c|c|c|c|c|c|c|}
\hline Group & tSOD & CuZn SOD & $\mathrm{Mn}$ SOD & CAT & GP & DSPC \\
\hline Endo-air & $88.2 \pm 30.6$ & $82.7 \pm 21.1$ & $21.3 \pm 7.6$ & $146.9 \pm 63.9$ & $0.706 \pm 0.246$ & $6.79 \pm 1.36$ \\
\hline Endo- $\mathrm{O}_{2}$ & $104.4 \pm 29.1^{*}$ & $98.8 \pm 23.5^{*}$ & $19.8 \pm 8.1$ & $162.5 \pm 59.6$ & $0.743 \pm 0.226$ & $6.47 \pm 1.32$ \\
\hline $\mathrm{O}_{2}$ vs air & $+18 \%$ & $+19 \%$ & $-7 \%$ & $+11 \%$ & $+5 \%$ & $-5 \%$ \\
\hline Cont-air & $73.3 \pm 22.8$ & $69.6 \pm 18.8$ & $26.7 \pm 4.3$ & $138.6 \pm 48.0$ & $0.746 \pm 0.168$ & $5.44 \pm 1.21$ \\
\hline Cont- $\mathrm{O}_{2}$ & $69.2 \pm 21.3$ & $72.5 \pm 11.0$ & $21.6 \pm 4.0^{*}$ & $141.3 \pm 65.1$ & $0.760 \pm 0.278$ & $5.12 \pm 0.86$ \\
\hline $\mathrm{O}_{2}$ vs air & $-6 \%$ & $+4 \%$ & $-19 \%$ & $+2 \%$ & $+2 \%$ & $-6 \%$ \\
\hline
\end{tabular}

Endo, endotoxin; Cont, control; tSOD, total SOD. Endotoxin: $n=33-51$ samples (lungs)/group. Control: $n=10-33$ samples (lungs)/group. Units: AOE, IU/mg DNA; DSPC, mg/g wet lung weight.

$* p<0.05\left(\mathrm{O}_{2}\right.$ values vs air values $)$. 
Table 2. AOE activities and lung DSPC after 48-h air or $>90 \% \mathrm{O}_{2}$ exposure in dexamethasone-treated and control 29.5-d preterm rabbits

\begin{tabular}{|c|c|c|c|c|}
\hline Group & tSOD & CAT & GP & DSPC \\
\hline Dexa-air & $69.9 \pm 25.5$ & $128.6 \pm 51.7$ & $0.955 \pm 0.475$ & $5.39 \pm 1.15$ \\
\hline $\mathrm{O}_{2}$ vs air & $-11 \%$ & $-11 \%$ & $-23 \%$ & $0 \%$ \\
\hline \multicolumn{5}{|c|}{ Postnatal dexamethasone } \\
\hline Dexa-air & $114.2 \pm 33.7$ & $228.3 \pm 37.3$ & $0.848 \pm 0.019$ & $6.40 \pm 0.58$ \\
\hline Dexa- $\mathrm{O}_{2}$ & $114.6 \pm 12.7$ & $248.0 \pm 31.3$ & $0.831 \pm 0.081$ & $7.01 \pm 0.43$ \\
\hline Cont-air & $78.8 \pm 30.1$ & $138.8 \pm 39.9$ & $0.682 \pm 0.314$ & $5.28 \pm 0.91$ \\
\hline Cont $-\mathrm{O}_{2}$ & $80.0 \pm 31.0$ & $140.5 \pm 41.3$ & $0.708 \pm 0.290$ & $5.08 \pm 1.13$ \\
\hline $\mathrm{O}_{2}$ vs air & $+1 \%$ & $+1 \%$ & $+4 \%$ & $-4 \%$ \\
\hline
\end{tabular}

Dexa, dexamethasonc; Cont, control; tSOD, total SOD. Dexamethasone: Prenatal, $n=27-30$ samples (lungs)/group; postnatal, $n=8$. Control: $n=15-23$ samples (lungs)/group. No differences are statistically significant.

mRNA $(+14 \%)$, CAT mRNA $(+19 \%)$, and GP mRNA $(+23 \%$ ) (Fig. $1 A)$. (Numbers represent percent changes when 48-h hyperoxia-exposed lung AOE values are compared with 48-h air-exposed values.) Full-term rabbits exhibited a different response to hyperoxia. In association with the significant increase in CuZn SOD activity $(+31 \%, p<0.05)$ after 48 h of hyperoxic exposure, full-term rabbits had a corresponding significant increase in CuZn SOD mRNA $(+45 \%, p<0.05)$.
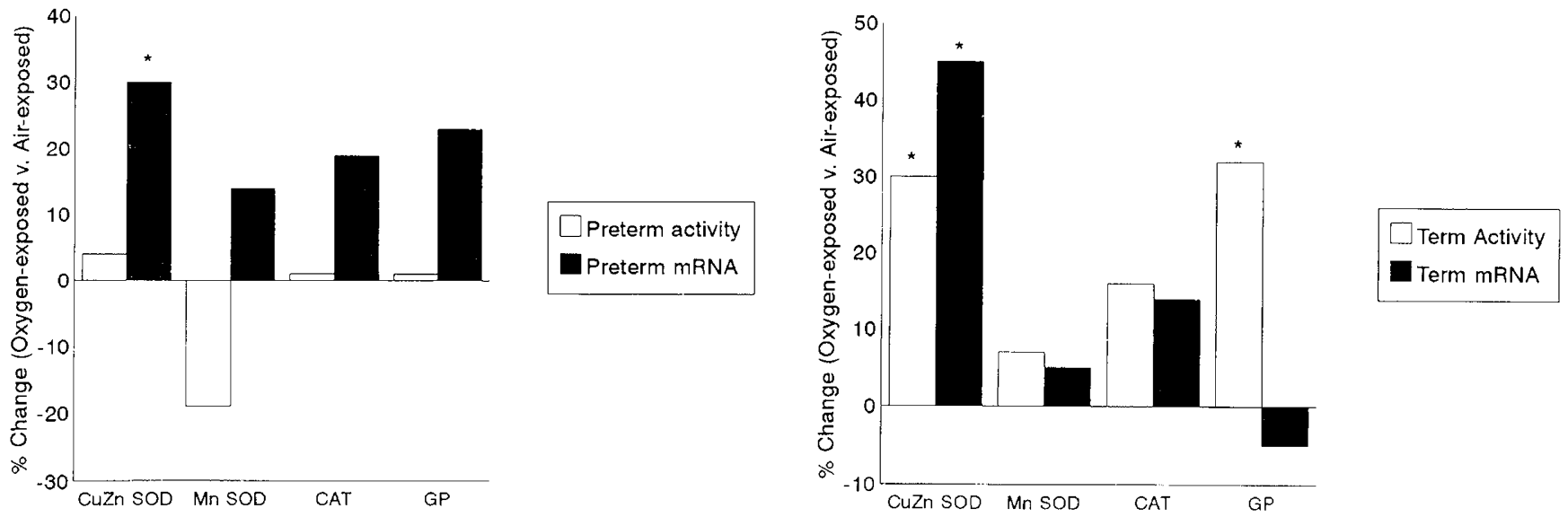

(C) Antioxidant enzyme activity and mRNA response to hyperoxia: Endotoxin-treated Rabbits

(D) Antioxidant enzyme activity and mRNA response to hyperoxia: Dexamethasone-treated Rabbits
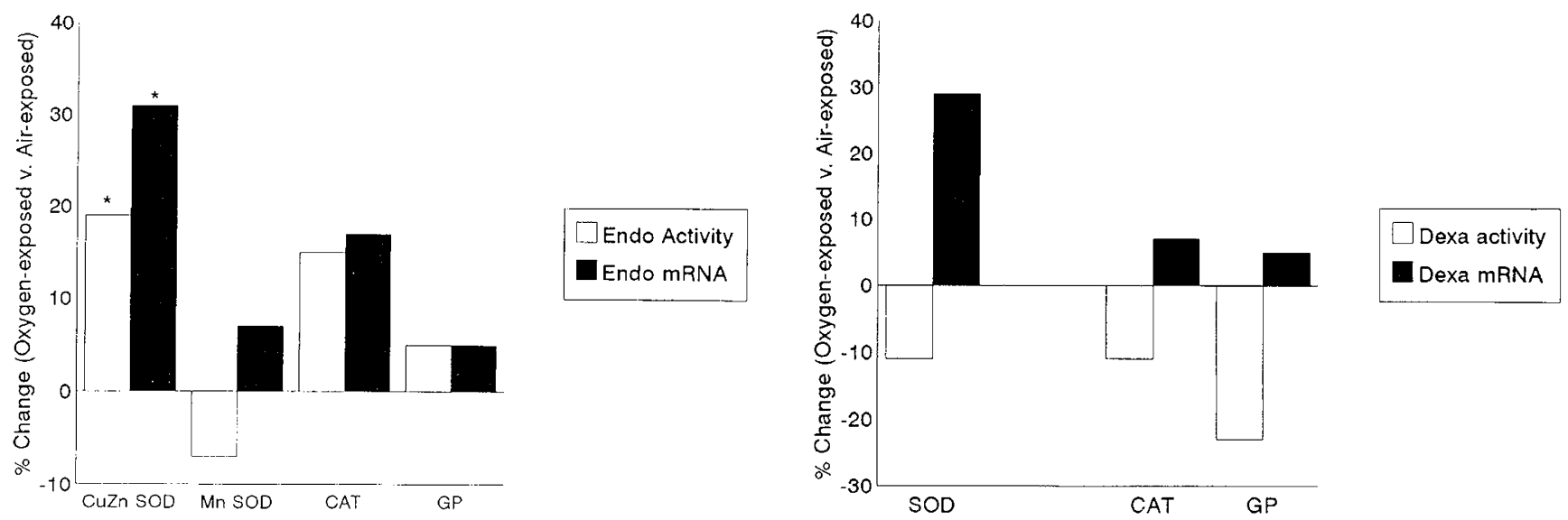

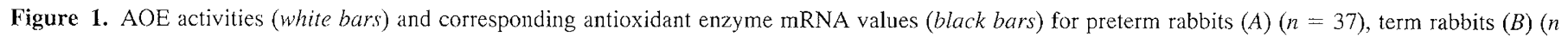
$=17)$, endotoxin-treated preterm rabbits $(C)(n=27)$, and dexamethasone-exposed preterm rabbits $(D)(n=20)$. Values represent percent changes when 48 -h hypcroxia values are compared with 48 -h air values. For the dexamethasone-treated group $(D)$ only, SOD activity represents total SOD activity; SOD mRNA represents CuZn SOD mRNA. 
The changes in Mn SOD mRNA (+5\%) and CAT mRNA $(+14 \%)$, although not significant, were of a magnitude similar to that of the AOE activity changes (Mn SOD activity: $+7 \%$; CAT activity: $+16.5 \%$ ) (Fig. $1 B$ ). Despite the significant increase in GP activity $(+32 \%, p<0.05)$, GP mRNA was decreased $5 \%$ in term rabbits.

Endotoxin experiments. At the dosing range of 20-40 $\mu \mathrm{g} / \mathrm{kg} / \mathrm{d}$, endotoxin-injected 29.5 -d preterm rabbits demonstrated no significant differences in 48 -h weights or in lung wet weight compared with saline control preterm rabbits. After a 48-h exposure period to $>90 \% \mathrm{O}_{2}$, postnatal endotoxin administration resulted in significant increases in activities of total lung SOD $(+18 \%, p<0.05)$ and CuZn SOD $(+20 \%, p<$ $0.05)$ without producing significant changes in $\mathrm{Mn}$ SOD $(-7 \%)$, CAT $(+11 \%)$, or GP $(+5 \%)$ activities (Table 1, Fig. $1 C)$ in 29.5-d preterm rabbit lungs. (Numbers represent percent changes when 48-h hyperoxia-exposed lung AOE values are compared with 48-h air-exposed values.) During the same 48-h hyperoxic exposure period, saline-injected 29.5-d preterm rabbits demonstrated no increases in total SOD $(-6 \%)$, CuZn SOD $(+4 \%)$, CAT $(+2 \%)$, or GP $(+2 \%)$ activities and a significant decrease in Mn SOD activity $(-19 \%, p<0.05)$ (Table 1). No significant differences were present after $48 \mathrm{~h}$ of hyperoxia in lung DSPC content in either endotoxin-treated $(-5 \%)$ or saline control $(-6 \%) 29.5-\mathrm{d}$ preterm rabbits (Table 1).

Endotoxin-treated preterm rabbits demonstrated significant increases in CuZn SOD mRNA $(+31 \%, p<0.05)$ but no significant increases in Mn SOD mRNA (+7\%), CAT mRNA $(+17 \%)$, or GP mRNA $(+6 \%)$ compared with their AOE activity responses to hyperoxia (Table 1, Fig. 1C). The small, statistically insignificant changes in the CAT and GP mRNA were of a magnitude similar to that of the small changes in specific AOE activities after 48 h of hyperoxia (Fig. 1C).

In terms of indices of $\mathrm{O}_{2}$ toxicity, endotoxin-treatment did not significantly influence survival after $48 \mathrm{~h}$ of air exposure ( $>90 \%$ survival for both preterm endotoxin-treated and controls). However, after $48 \mathrm{~h}$ of hyperoxic exposure, endotoxintreated 29.5-d preterm rabbits demonstrated significantly improved survival compared with saline-injected controls $(74 / 81$ $=91 \%$ versus $70 / 92=76 \%$, respectively; $p<0.05$ ). Hyperoxia caused a significant increase in lung lavage fluid protein content in saline-injected preterm rabbits compared with airexposed controls $(+28 \%, p<0.05)$. Endotoxin treatment protected against this toxic response to hyperoxia (lavage protein increase in hypcroxia-exposed versus air-exposed endotoxin-treated preterm rabbits, $+4 \%$ ). However, no differences were found between endotoxin and saline control groups in wet lung/dry lung weight ratios after $48 \mathrm{~h}$ of hyperoxic exposure.

Dexamethasone experiments. At the dosing range of $0.01-$ $0.05 \mathrm{mg} / \mathrm{kg}$ maternal body weight, prenatal dexamethasone treatment resulted in a significant decrease in birth weight of 29.5 -d preterm rabbits $(-23 \%, p<0.05)$ and a corresponding decrease in weights at $48 \mathrm{~h}$, without any differences in lung wet weight compared with control preterm rabbits. Prenatal dexamethasone administration followed by a 48-h exposure to $>90 \% \mathrm{O}_{2}$ resulted in no significant increases in activities of total SOD $(-11 \%)$, CAT $(-11 \%)$, or GP $(-23 \%)$ (Table 2 , Fig. 1D) in 29.5-d preterm rabbit lungs. (Numbers represent percent changes when 48-h hyperoxia Iung AOE values are compared with 48-h air values.) During the same 48-h hyperoxic exposure period, simultaneously exposed saline-injected 29.5-d preterm rabbits also demonstrated no increases in total SOD $(+1 \%)$, CAT $(+1 \%)$, or GP $(+4 \%)$ activities. No significant differences were present after $48 \mathrm{~h}$ of hyperoxia in lung DSPC content (Tablc 2) in either dexamethasone-treated $(0 \%)$ or saline control $(-4 \%) 29.5-\mathrm{d}$ preterm rabbits. Similarly, when dexamethasone-exposed 29.5 -d preterm rabbits were compared with saline controls at the time of birth before air breathing, values for AOE activitics and lung DSPC content were not different between dexamethasone and control preterm rabbits, respectively (total SOD: $35.5 \pm 15.2$ versus $39.3 \pm$ 10.0; CAT: $49.0 \pm 13.5$ versus $42.2 \pm 9.3$; GP: $0.399 \pm 0.124$ versus $0.390 \pm 0.077 \mathrm{IU} / \mathrm{mg}$ DNA; DSPC: $2.69 \pm 0.47$ versus $2.73 \pm 0.84 \mathrm{mg} / \mathrm{g}$ wet lung weight). Finally, in the one cxperiment where dexamethasone was administered postnatally at a dose of $5 \mu \mathrm{g} / \mathrm{kg}$, no significant increases were present after 48 h of hyperoxia in either AOE activities or lung DSPC content (Table 2).

Dexamethasone-treated preterm rabbits demonstrated no significant increase in CuZn SOD mRNA $(+29 \%)$, CAT mRNA $(+7 \%)$, or GP mRNA (+5\%) (Fig. $1 D)$ or in Mn SOD mRNA $(7 \%)$ in association with their lack of hyperoxic increase in AOE activitics (Table 2, Fig. 1D).

Dexamethasone-exposed preterm rabbits delivered at $29.5 \mathrm{~d}$ demonstrated decreased survival after $48 \mathrm{~h}$ of normoxic cxposure $(46 / 93=49 \%$ compared with $44 / 52=85 \%$ in controls, $p$ $<0.01$.). Furthermore, dexamethasonc-treated preterm rabbits did even less well after $48 \mathrm{~h}$ of exposure to $>90 \% \mathrm{O}_{2}(44 / 126$ $=35 \%)$ when compared with either normoxia-cxposed dexamethasone preterm rabbits $(46 / 93=49 \%, p<0.05 \%)$ or hyperoxia-exposed control preterm rabbits $(52 / 71=73 \%, p<$ 0.01 ). However, the response to $48 \mathrm{~h}$ of hyperoxia was not different for dexamethasone versus control offspring in terms of lung lavage fluid protein content or in wet lung/dry lung weight ratios (data not shown).

\section{DISCUSSION}

Among the proposed etiologies for chronic lung disease in the preterm human infant are the immature devclopment of the protective AOE system of the lung plus the inability to induce increases in pulmonary AOE activities to counteract the increased free-radical production associated with hyperoxic cxposure. Although not yet definitively investigated in the preterm human infant, this phenomenon has been found in the preterm rabbit in our previous investigation (3) and confirmed in the present investigation. At $29.5 \mathrm{~d}$ of gestation, the newly delivered rabbit is unable to mount a protective hyperoxic $\mathrm{AOE}$ activity response and shows increased evidence of pulmonary $\mathrm{O}_{2}$ toxicity compared with the full-term newborn rabbit. These findings for the preterm rabbit are consistent with findings in the premature baboon, a spccies that is also unable to increase AOE activities with hyperoxic exposure (19). However, a recent study from our laboratory has reported unexpectedly 
different findings in the developing rat. Specifically, rats delivered $1 \mathrm{~d}$ prematurely had significantly increased activities of CuZn SOD, CAT, and GP and lung DSPC content (increases of a magnitude comparable to that in term rats exposed to hyperoxia), with increased survival rates in hyperoxia and decreased indices of $\mathrm{O}_{2}$ toxicity (20).

To investigate the molecular basis for the lack of hyperoxic $\mathrm{AOE}$ induction in the preterm rabbit, the present study examined gene expression of the AOE after hyperoxic exposure in rabbits of preterm and term gestation. Although we had anticipated that the preterm rabbit's inability to increase AOE activities during hyperoxia would be related to a pretranslational defect in gene cxpression, our findings of a significant increase in CuZn SOD mRNA (with smaller, not statistically significant, increases in all AOE mRNA) without corresponding activity increases were unexpected and suggest translation$\mathrm{al} /$ posttranslational inhibition of $\mathrm{AOE}$ gene expression in the preterm rabbit lung. For the term rabbit, we had anticipated increased $\mathrm{AOE}$ gene expression via pretranslational mechanisms, with increases in AOE mRNA associated with concordant increases in AOE activities. This phenomenon seemed to be present for CuZn SOD (activity: $+30 \%$, mRNA: $+45 \%$; both $p<0.05$ ) and possibly CAT (activity: $+16 \%$, mRNA: $+14 \%$; neither increase was statistically significant). However, the significant increase in GP activity $(+32 \%, p<0.05)$ without increase in GP mRNA (-5\%) suggests that GP activity changes may be regulated by a different mechanism, such as translational/posttranslational stimulation, or by a posttranscriptional mechanism involving increased rate of enzyme synthesis and/or increased stability of the enzyme. The finding that all of the AOE are not coordinately regulated in their gene expression responses to hyperoxia is consistent with previous developmental studies of the AOE in fetal and neonatal lungs $(12,20)$.

Bacterial endotoxin treatment (the complex lipopolysaccharide found in the cell wall of Gram-negative bacteria) enables adult rats, normally very $\mathrm{O}_{2}$ intolerant and unable to increase AOE activities with hyperoxic exposure, to become significantly more oxygen tolerant and to demonstrate rapid lung AOE induction with hyperoxia. This response is regulated pretranslationally and consists of increases in both AOE activity levels as well as increases in AOE mRNA levels (13, 21-23). Based on these previous findings, we hypothesized that postnatal endotoxin administered to 29.5 -d preterm rabbits would improve $\mathrm{O}_{2}$ tolerance and induce hyperoxic increases in AOE mRNA that would then lead to increased pulmonary AOE activities. In fact, that is what our data clearly demonstrated for CuZn SOD. The endotoxin-treated preterm rabbits had significantly improved hyperoxic survival, evidence of decreased $\mathrm{O}_{2}$ toxicity, and demonstrated significant increases in both CuZn SOD activity and mRNA, suggesting pretranslational regulation in response to hyperoxic exposure, similar to what was found for the untreated term rabbit. These findings also suggest that endotoxin reverses the translational/ posttranslational inhibition of CuZn SOD gene expression characteristic of the preterm rabbit. One possible mechanism of this reversal by endotoxin may be through elevations in levels of specific cytokines such as tumor necrosis factor, IL-1, IL-6, or platelet-derived growth factor; the synthesis of these cytokines has been demonstrated to be increased as a result of endotoxin (24).

Multiple lines of experimental evidence provided impetus for the hypothesis that glucocorticoids would enhance the maturation of the preterm rabbit lung and thereby reverse the inability to mount a protective hyperoxic AOE response. Prenatal dexamethasone treatment in the rat is associated with improved neonatal hyperoxic survival, decreased indices of $\mathrm{O}_{2}$ toxicity, and greater and more rapid AOE responses to hyperoxia (25). Furthermore, glucocorticoids have been used clinically for acceleration of lung maturity in threatened premature delivery. The results of the present investigation in the preterm rabbit, in which antenatal glucocorticoids were unable to reverse the rabbit's inability to increase AOE activities with hyperoxia, were at variance with these experimental and clinical findings. A possible explanation for this discrepancy is species specificity of the positive effect of glucocorticoids on the developing lung, which although present in rat and human may be different in the rabbit. For example, rabbits seem to have increased sensitivity to the negative effects of low-dose prenatal glucocorticoids (e.g. growth retardation, decreased fetal survival) without manifesting evidence of enhanced lung maturation $(26-29)$. This seemed to be the case in our present investigation (significantly decreased fetal weight and decreased 48-h normoxic survival but no evidence of enhanced lung maturity). There is also the possibility that dexamethasone failed to have any positive effect in our experimental rabbits due to the relatively late timing of treatments (gestational d 27.5 and 28.5). Evidence from other studies suggests that the peak "positive" maturational effect in the fetal rabbit lung may result from treatment at 25 and $26 \mathrm{~d}$ of gestation (30).

In conclusion, these results suggest that the inability of the preterm rabbit to induce a protective hyperoxic $\mathrm{AOE}$ activity increase is related to translational/posttranslational inhibition of AOE gene expression, a mechanism different from the pretranslational control present in the full-term rabbit. Postnatal endotoxin treatment (but not dexamethasone administration) seems to partially protect against $\mathrm{O}_{2}$ toxicity and to reverse the translational/posttranslational inhibition of $\mathrm{AOE}$ gene expression characteristic of the preterm rabbit.

Acknowledgments. The authors thank Miguel Martinez for his excellent technical support and Dr. Heber Nielsen for his critical review of and suggestions for the manuscript.

\section{REFERENCES}

1. Bancalari E, Sosenko I 1990 Pathogenesis and prevention of neonatal chronic lung disease: recent developments. Pediatr Pulmonol 8:109-116

2. Frank L, Bucher JR, Roberts RJ 1978 Oxygen toxicity in neonatal and adult animals of various species. J Appl Physiol 45:699-704

3. Frank L, Sosenko IRS 1991 Failure of premature rabbits to increase antioxidant enzymes during hyperoxic exposure: increased susceptibility to pulmonary oxygen toxicity. Pediatr Res 29:292-296

4. Aprille JR, Rulfs J 1976 A convenient neonatal method for developmental studies requiring artificial diets. Biol Neonate 30:109-115

5. McCord JM, Fridovich I 1969 Superoxide dismutase: an enzymic function for erythrocuprein (hemocuprein). J Biol Chem 244:6049-6055

6. Holmes RS, Masters CJ 1970 Epigenetic interconversion of the multiple forms of mouse liver catalase. FEBS Lett 11:45-48

7. Paglia DE, Valentine WN 1967 Studies on the quantitative and qualitative characterization of erythrocytc glutathione peroxidase. J Lab Clin Med 70:158-159 
8. Iqbal J, Whitney P 1991 Use of cyanide and diethyldithiocarbamate in the assay of superoxide dismutases. Free Radic Biol Med 10:69-77

9. Richards G 1974 Modifications of the diphenylamine reactions giving increased sensitivity and simplicity in the estimation of DNA. Anal Biochem 57:369-376

10. Schacterle RE, Pollack RL 1973 A simplified method for the quantitative assay of small amounts of protcin in biological material. Anal Biochem 51:654-655

11. Chen Y, Whitney P, Frank L 1993 Negative regulation of antioxidant enzyme gene expression in the developing fetal rat lung by prenatal hormonal treatments. Pediatr Res 33:171-176

12. Chen Y, Frank L 1993 Differential gene expression of antioxidant enzymes in the perinatal rat lung. Pediatr Res 34:27-31

13. Hass MA, Iqbal J, Clerch LB, Frank L, Massaro D 1989 Rat lung $\mathrm{Cu}, \mathrm{Zn}$ superoxide dismutase: isolation and sequence of a full-length cDNA and studies of enzymo induction. J Clin Invest 83:1241-1246

14. Durnam DM, Palmiter RD 1983 A practical approach for quantitating specific mRNAs by solution hybridization. Anal Biochem 131:385-393

15. Bligh EF, Dyer WJ 1959 A rapid method of total lipid extraction and purification. Can J Biochem Physiol 37:911-917

16. Mason RJ, Nellenbogen J, Clements JA 1976 Isolation of disaturated phosphatidylcholine with osmium tetroxide. J Lipid Res 17:281-284

17. Morrison WR $1964 \mathrm{~A}$ fast, simple and reliable method for the microdetermination of phosphorus in biological materials. Anal Biochem 11:218-224

18. Fisher RA 1970 Statistical Methods for Research Workers. Hafner Press, New York pp 213-224

19. Jenkinson SG, Roberts RJ, DeLemos RA, Lawrence RA, Coalson JJ, King RJ, Null DM, Gerstmann DR 1991 Allopurinol-induced effects in premature baboons with respiratory distress syndrome. J Appl Physiol 70:1160-1167
20. Chen Y, Whitney P, Frank L 1994 Comparative responses of premature versus full-term newborn rats to prolonged hyperoxia. Pediatr Res 35:233-237

21. Iqbal J, Cierch LB, Hass MA, Frank L, Massaro D 1989 Endotoxin increases lun $\mathrm{CuZn}$ supcroxide dismutase mRNA: $\mathrm{O}_{2}$ raises enzyme synthesis. Am J Physiol 257:L61-L64

22. Frank L, Yam J, Roberts RJ 1978 The role of endotoxin in protection of adult rats from high oxygen lung toxicity. J Clin Invest 61:269-275

23. Fanburg BL, Massaro DJ, Cerutti PA, Gail DB, Berberich MA 1992 Regulation of gene expression by $\mathrm{O}_{2}$ tension (conference report). Am J Physiol 262:L235-L241

24. Van Deventer SJH, Buller HR, ten Cate JW, Aarden LA, Hack CE, Sturk A 1990 Experimental endotoxemia in humans: analysis of cytokine release and coagulation, fibrinolytic, and complement pathways. Blood 76:2520-2526

25. Frank L 1992 Prenatal dexamethasone treatment improves survival of newborn rats during prolonged high oxygen exposure. Pediatr Res 32:215-221

26. Sun B, Jobe A, Rider E, Ikegami M 1993 Single dose versus two doses of betamethasone for lung maturation in preterm rabbits. Pediatr Res 33:256-260

27. Ikegami M, Berry D, Elkady T, Pettenazzo A, Scidner S, Jobe A 1987 Corticosteroids and surfactant change lung function and protein leaks in the lungs of ventilated premature rabbits. J Clin Invest 79:1371-1378

28. Motoyama K, Orzalesi MM, Kikkawa Y, Kaibara M, Wu B, Zigas CJ, Cook CD 197 Effect of cortisol on the maturation of fetal rabbit lungs. Pediatrics 48:547-555

29. Tabor BL, Rider ED, Ikegami M, Jobe AH, Lewis JF 1991 Dose effects of antenatil corticosteroids for induction of lung maturation in preterm rabbits. Am J Obstet Gynccol 164:675-681

30. Klein JM, Nielsen HC 1992 Sex specific differences in rabbit fetal lung maturation in response to epidermal growth factor. Biochem Biophys Acta 1133:121-126 